\section{West German AIDS research programme still in limbo \\ Munich}

ENTERING the fifth year of a national research programme on AIDS (acquired immune deficiency syndrome), West Germany is eager to be seen doing its part in the worldwide effort to combat the disease.

But, despite a proclamation by Chancellor Helmut Kohl that "no reasonable project will fail for lack of money", West Germany has yet to make a mark with its programme. The few research groups with an international reputation are scattered geographically, and coordination of the programme is loose.

Now the Federal research and technology ministry (BMFT) is hoping to remedy this state of affairs with a number of "special collaborative programmes" modelled on the Sonderforschungsbereichen of the DFG (Deutsche Forschungsgemeinschaft). A large group of Munich researchers has already applied for funds under this plan, while a group of about 50 researchers in Göttingen, Hannover and elsewhere is working on an application for DM 2.5 million.

Part of the explanation for the slow start is that AIDS came later to West Germany than to the United States. In 1983, when BMFT first allocated special funds for AIDS research, there were only 10 cases. Even now, there are fewer than 2,000. Since 1983, BMFT has spent just DM40 million (about $\$ 23$ million) for basic research, compared with the annual US AIDS research budget of more than $\$ 900$ stem from factors such as these: needed here. United States.
The root of the problem lies with the researchers themselves. According to Hermann Wagner, a professor at the University of Ulm and head of the panel appointed by BMFT to judge the new proposals, "there are not enough good applications" for the money available.

Nobody claims that West German researchers lack talent or interest. The shortage of strong proposals seems to

- Structure. BMFT, which funds 90 per cent of basic AIDS research, has departed from precedents elsewhere by not appointing a single person to supervise its AIDS programme and to identify new projects. The role played in the United States by Anthony Fauci of the National Institute of Allergy and Infectious Diseases of the National Institutes of Health is cited by many researchers as a model of what is

Instead, BMFT has appointed a committee to oversee its projects which, located in the Federal Health Office (Bundesgesundheitsamt or BGA) in West Berlin, is still feeling its way. In any event, BGA has much less than influence than the National Institutes of Health in the

Within the West German university system, it also seems difficult to channel the funds available to the young, able researchers most likely to want to work on AIDS, partly because research grants from BMFT or the DFG do not include

\section{Lowering the high risks of bad blood}

\section{Washington}

A JUST-released study estimating the risk of contracting AIDS (acquired immune deficiency syndrome) from a blood transfusion at about one in $\mathbf{4 0 , 0 0 0}$ is already out of date, according to Gerald Sandler, deputy director of the American Red Cross. New screening procedures ensure that the risk is much lower, he says.

The study, published in last week's $\mathrm{New}$ England Journal of Medicine (318, 473; 1988), documents 13 cases where transfusion recipients became infected after receiving blood that had passed routine screening tests. The donors were later found to be positive for HIV antibodies, suggesting that they had donated blood after infection but before their antibody responses had developed to detectable levels. Five of the seven donors had been homosexually active and one had had sexual contact with an intravenous drug user.

Estimates of risk based on this study are too high, according to Sandler, because new procedures help to exclude high-risk groups from donating blood and because antibody-screening tests are now more sensitive. The estimate was in any case pessimistic because it was a worst-case analysis, with data collected in high-risk areas.

Since the study was conducted, new procedures allow active homosexuals and others at risk to specify that their blood donation be used for experiment rather than transfusion.

But voluntary self-exclusion is not the only approach being pursued. Commercially available ELISA (enzyme-linked immunosorbent assay) kits for antibody detection are now more sensitive and have increased the chances of early detection. Tests for the presence of viral antigen are also in the pipeline and may turn out to be even more effective. The American Association of Blood Banks says its members will quickly make use of any new advances. "basic equipment" or laboratory space, all of which must be provided by the university, which then also has to pay much of the overhead costs of equipment.

One bizarre consequence of this arrangement in all research fields is that universities do not encourage outside research support for fear that their own costs will escalate. This problem ultimately traces back to the sovereignty of the Länder (states), not the federal government, over universities.

- Culture. The zeal to work on AIDS evident in the United States is missing in West Germany. One group of researchers returned from the United States impressed that finding a treatment or a vaccine for AIDS had become a kind of "national mission". But DFG President Hubert Markl rejects the "big mission" strategy for West Germany, saying that each country has its own best way of attacking problems. Although the "bandwagon approach" had been very successful in the United States, he says that in West Germany, "you can marshal more support by offering a base for future research". Markl admits that, so far, this approach has not produced "research at the cutting edge".

- History. West Germany is hampered by the lack of a centre for virology research. Ironically, there used to be one, a Max Planck Institute at Tübingen, but that was gradually reoriented in the 1970 s to its current focus on developmental biology.

Many of those now working on AIDS cut their teeth at Tübingen under the virologist Werner Schäfer. Thus Gerhard Hunsmann, at the German Primate Centre at Göttingen, is supported by BMFT and European Community funds in a search for a primate model for AIDS other than the chimpanzee.Reinhard Kurth, at the Paul Ehrlich Institute in Frankfurt, is collaborating in the study of simian viruses with groups in the United States in a search for clues to a vaccine. Other Schäfer alumni are in West Berlin, Heidelberg and the United States, while there are also internationally competitive groups of virologists at Munich and Erlangen.

BMFT hopes that its new scheme will help overcome geographic separation and generally stimulate virology and related research, but some researchers are sceptical, noting that the necessary structural changes in the university system will not happen, as one put it, "unless we have a revolution or people are dying in the streets".

But others are more optimistic, saying that BMFT and the BGA are doing reasonably well, given that they started late. They point to the reputation of West German researchers in immunology, electron microscopy and related fields. But only time will tell how effective BMFT initiative in AIDS research will be. Steven Dickman 